bipolar disorder are because of a breakdown in communication between neurons and glia, which occurs most potently at the tripartite synapse. Our published data and recent data from our microarray study have now shown that there is a decrease in the expression of specific apolipoprotein E receptors in the CNS of subjects with schizophrenia, further supporting our hypotheses of altered neuronal glia communication in psychiatric disease and will be summarized in this presentation.

\section{Time course of illness prior to a diagnosis of bipolar disorder or schizoaffective disorder}

\section{S Dodd', J Kulkarni'2, F Biffin², S Tahtalian², K Filia², S Filia ${ }^{2}$, A de Castella ${ }^{2}$, P Fitzgerald ${ }^{2}$, W Montgomery ${ }^{3}$, K Kelin ${ }^{3}$, M Smith ${ }^{4}$, L Berk ${ }^{5}$, M Berk ${ }^{5}$, P Callaly ${ }^{5}$}

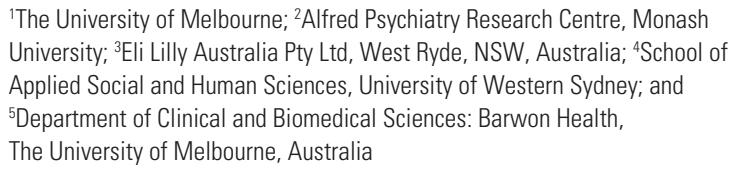

Background: Evidence suggests that diagnostic delay from first episode of illness may be many years. Treating illness early in its time course is associated with a better prognosis.

Methods: Participants $(n=240)$ were enrolled in the Bipolar Comprehensive Outcomes Study (BCOS). A questionnaire was devised to collect information about participants from their first onset of symptoms of mental illness to when they received a diagnosis of bipolar disorder or schizoaffective disorder. The questionnaire was administered at interview by BCOS researchers when the participant was euthymic.

Results: Symptoms of mental illness were first experienced at $20.17 \pm 10.26$ years (mean $\pm \mathrm{SD} ; n=207$ ) and mood swings at $21.19 \pm 11.76$ years (mean \pm SD; $n=191$ ). Symptoms of depression were first experienced at $21.11 \pm 9.98$ years (mean $\pm \mathrm{SD} ; n=195)$, a full episode of depression at $23.64 \pm 9.76$ years $($ mean $\pm \mathrm{SD}$; $n=191$ ), symptoms of mania at $24.24 \pm 11.48$ years (mean $\pm \mathrm{SD} ; n=202$ ) and a full episode of mania at $26.43 \pm 10.41$ years (mean $\pm \mathrm{SD} ; n=196)$. Medical treatment was first sought at $26.26 \pm 10.18$ years (mean $\pm \mathrm{SD} ; n=207$ ). Participants first received a diagnosis of bipolar disorder or schizoaffective disorder at $31.43 \pm 11.34$ years (mean $\pm \mathrm{SD} ; n=206$ ). Having had a previous diagnosis other than bipolar disorder or schizoaffective disorder was reported by 116 of 206 participants who answered this question.

Conclusions: Prior to being diagnosed and treated for bipolar disorder or schizoaffective disorder, partici- pants typically experience a long time course of symptoms, episode and treatments.

\section{A central dilemma in the mental health sector: structural imbalance}

\section{Doessel'1, R Williams², P Nolan'}

${ }^{1}$ Queensland Centre for Mental Health Research (OCMHR), Brisbane, Australia; ${ }^{2}$ School of Applied Economics and Centre for Strategic Economic Studies, Victoria University, Melbourne, Australia

Background: The provision of mental health services is subject to persistent criticism, often with the implication that allocated resources are inadequate. However, the mental health sector is also subject to another dilemma, which we define as a 'structural imbalance' problem.

Methods: The study shows the dimensions of structural imbalance in Australia's mental health sector by recourse to two data sets: the Mental Health and Wellbeing: Profile of Adults, Australia 1997, published by the ABS; and the National Minimum Data Set - Institutional Mental Health Services published by the AIHW. This study also examines the concept by reference to the Australian Government's COAG mental health initiatives announced in April and state government responses in July 2006.

Results: The two dimensions of the structural imbalance are 1) that some people, with no clinical manifestations of mental illness, consume mental health services and 2) another group of people have clinical manifestations of mental illness but (for various reasons) do not consume mental health services. We show how the situation coexists with various patterns of resource distribution in the public and private health sectors, acute vs. chronic conditions, institutional vs. noninstitutional service provision and private vs. public medical practice.

Conclusions: 'Throwing more money' at the preexisting structures will do nothing to address the structural imbalance problem. Remedies are discussed by reference to the content and processes of reform undertaken in the British National Health Service in recent years.

\section{Anxiety, depression and the HPA axis in human pregnancy: links to postpartum mood}

\section{K-A Egliston', M-P Austin², C McMahon ${ }^{3}$}

The Black Dog Institute; ${ }^{2}$ School of Psychiatry, UNSW; and ${ }^{3}$ Macquarie University, Sydney, Australia

Background: Most studies investigating maternal mood across the transition from pregnancy to the postnatal period have focused on depression. In contrast, 